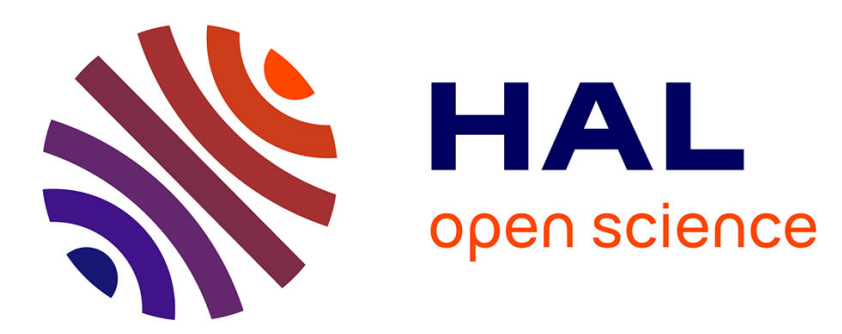

\title{
Abundance, richness and composition of lianas in forest communities along an elevation gradient in New Caledonia
}

David Bruy, Thomas Ibanez, Jérôme Munzinger, Sandrine Isnard

\section{- To cite this version:}

David Bruy, Thomas Ibanez, Jérôme Munzinger, Sandrine Isnard. Abundance, richness and composition of lianas in forest communities along an elevation gradient in New Caledonia. Plant ecology \& diversity, 2017, 10 (5-6), pp.469 - 481. 10.1080/17550874.2018.1430186 . hal-01851491

\section{HAL Id: hal-01851491 \\ https://hal.umontpellier.fr/hal-01851491}

Submitted on 27 Apr 2020

HAL is a multi-disciplinary open access archive for the deposit and dissemination of scientific research documents, whether they are published or not. The documents may come from teaching and research institutions in France or abroad, or from public or private research centers.
L'archive ouverte pluridisciplinaire HAL, est destinée au dépôt et à la diffusion de documents scientifiques de niveau recherche, publiés ou non, émanant des établissements d'enseignement et de recherche français ou étrangers, des laboratoires publics ou privés. 


\section{Abundance, richness and composition of lianas in forest communities along an elevation gradient in New Caledonia}

David Bruy, Thomas Ibanez, Jérôme Munzinger \& Sandrine Isnard

To cite this article: David Bruy, Thomas Ibanez, Jérôme Munzinger \& Sandrine Isnard (2017) Abundance, richness and composition of lianas in forest communities along an elevation gradient in New Caledonia, Plant Ecology \& Diversity, 10:5-6, 469-481, DOI: $10.1080 / 17550874.2018 .1430186$

To link to this article: https://doi.org/10.1080/17550874.2018.1430186

曲 Published online: 09 Feb 2018.

Submit your article to this journal ๘

Џ Article views: 71

Q View related articles $\longleftarrow$

View Crossmark data ¿ 


\title{
Abundance, richness and composition of lianas in forest communities along an elevation gradient in New Caledonia
}

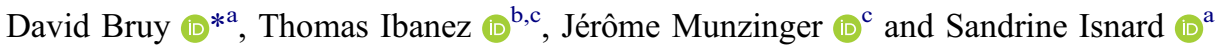 \\ ${ }^{a} A M A P, I R D, C I R A D, C N R S$, INRA, Université Montpellier, Nouméa, New Caledonia; ${ }^{b}$ Institut Agronomique néo-Calédonien (IAC), \\ Equipe Sol \& Végétation (SolVeg), Nouméa, New Caledonia; ${ }^{c} A M A P, I R D, C I R A D$, CNRS, INRA, Université Montpellier, Montpellier, \\ France
}

(Received 3 August 2016; accepted 4 January 2018)

\begin{abstract}
Background: Lianas are an abundantand dynamic component of tropical forests, and their abundance ispredicted to increase with global change. A better understandingof factors that explain their distribution is required, especially onoceanic islands for which few data are available.

Aims: Identifythe environmental factors that shape liana communities in NewCaledonian forests

Methods: We studied liana abundance,basal area, richness and climbing modes in 27 forest plots $(20 \mathrm{~m} \times 20 \mathrm{~m})$ along an elevation gradient (sea level to ca. 1000 ma.s.l.) that covers different forest types and precipitation regimes.

Results: We inventoried 992 lianas belonging to 71 species. The abundance and basal area decreased logarithmically withincreasing elevation while species richness tended to peak at midelevations. Twining lianas were the most abundant and species-richfunctional group. We found no clear relationship between climbingmodes and forest structure.

Conclusions: Our results show thatliana abundance decreases with increasing elevation in responseto lower precipitation in seasonal dry forest. At high elevation (600-1000 m a.s.1.), climbing secondary hemi-epiphytes replace lianasprobably as a result of climate-based niche differentiation. Variationof species richness along the gradient could not be explained byprecipitation or by forest structural parameters.
\end{abstract}

Keywords: climbers; climbing secondary hemi-epiphytes; climbing modes; diversity; forest structure; oceanic island; twining

\section{Introduction}

Lianas usually represent about $25 \%$ of woody stems and woody species in tropical forest which makes the abundance and richness of lianas one of the most singular structural features of these ecosystems (Gentry 1991; Schnitzer and Bongers 2002; Schnitzer et al. 2015b). Lianas also play an important role in tropical forest dynamics and functioning by reducing tree survival, regeneration, growth and fertility (Putz 1984b; PérezSalicrup et al. 2004; Phillips et al. 2005; Ingwell et al. 2010; Toledo-Aceves 2015; Fadrique and Homeier 2016). Despite the structural and functional importance of lianas in tropical forests, the factors responsible for their local distribution are still poorly known, especially on islands (DeWalt et al. 2015).

Several studies have suggested that the abundance and biomass of lianas is increasing as a response to global changes, especially rising atmospheric $\mathrm{CO}_{2}$ concentrations, land use and climate change (Phillips et al. 2002; Wright et al. 2004; Ingwell et al. 2010; Schnitzer 2015). Lianas should benefit from increasing anthropogenic forest perturbation and fragmentation since they are commonly light-demanding plants and their establishment within forests is promoted by local disturbances (Campbell et al. 2015; Schnitzer et al. 2015a). Previous studies have shown that lianas might also benefit from rising atmospheric $\mathrm{CO}_{2}$ level (Granados and Korner 2002; Phillips et al. 2002) and increasing seasonal drought (Schnitzer 2015). The drastic increase in liana abundance and biomass has been considered as one of the key structural changes occurring in tropical forest due to global changes (Schnitzer and Bongers 2011).

The ecological importance of lianas and their potentially strong response to global changes has increased interest in assessing which environmental factors influence liana distributions (DeWalt et al. 2015) as liana communities are likely shaped by multiple factors related to their diversity in life history strategies and ecology. Liana abundance and basal area tend to be positively correlated with dry-season length and negatively correlated with precipitation, at least on a pantropical or regional scale (Gentry 1991; Schnitzer 2005; DeWalt et al. 2010, 2015; Parthasarathy et al. 2015). However, the effects of these water-related factors are less clear on liana diversity (DeWalt et al. 2015; but see Van Der Heijden and Phillips 2008), which appears to be more affected by minimum temperatures, since lianas are very sensitive to frost (Schnitzer and Bongers 2002; Jiménez-Castillo et al. 2007; Jiménez-Castillo and Lusk 2013).

Local liana abundance and diversity should be affected by the availability of support and structural attributes of 
vegetation. Attributes such as tree diameter (Balfour and Bond 1993; Talley et al. 1996; Nabe-Nielsen 2001; Rice et al. 2004; Phillips et al. 2005; Homeier et al. 2010), canopy height (Baars et al. 1998; Balfour and Bond 1993; Dewalt et al. 2000; Gerwing and Farias 2000), tree architecture (Putz 1984a; Hegarty 1991), crown features (Putz 1984b; Balfour and Bond 1993) and tree density (Nabe-Nielsen 2001; Van Der Heijden and Phillips 2008) have been related to liana abundance and, to a lesser extent, liana diversity. Because lianas use different mechanisms for climbing, the interaction between climbing modes and forest structure is thought to strongly influence their distribution in forests (Putz 1984b; Putz and Chai 1987; Hegarty and Caballé 1991; Putz and Holbrook 1991; Dewalt et al. 2000; Nabe-Nielsen 2001; Parthasarathy et al. 2015). As such, local liana diversity could be more strongly affected by the structural heterogeneity of forests than by any specific forest structural features. Indeed, higher structural heterogeneity should provide a higher diversity of suitable supports, and an increase in niche diversity (Sfair and Martins 2011).

While most liana studies have been carried out in continental forests, data from island ecosystems remain scarce (DeWalt et al. 2015; Schnitzer et al. 2015b). This is a particular cause for concern since island ecosystems are very sensitive to habitat loss and global warming (Kier et al. 2009; Taylor and Kumar 2016). The few existing liana inventories in tropical islands suggest that both abundance and diversity are lower than in mainland sites (Gentry 1991; Rice et al. 2004; DeWalt et al. 2015). The few studies also suggest that climbing secondary hemiepiphytes (SHE) or 'nomad vines' (climbing plants germinating on the floor and loosing stem contact therewith, cf. Zotz 2013, for nomenclatural review), which are usually not considered in liana censuses, could significantly contribute to forest structure in these islands (Kelly 1985; DeWalt et al. 2015).

The objective of this study was to understand which factors affect liana communities in the tropical island of
New Caledonia; a biodiversity hotspot located in the Pacific Ocean (Myers et al. 2000). The main island of New Caledonia (called 'Grande Terre') is traversed from northwest to southeast by a central mountain range that determines the local climate. This marked topography offers ideal gradients on which to study the response of plant communities to climate and forest structure (see Korner 2007). We hypothesised that liana abundance would be negatively affected by precipitation and liana richness would be positively affected by forest structural features, especially tree size heterogeneity (TSH) that might promote the establishment of different climbing modes.

\section{Materials and methods}

\section{Study sites}

New Caledonia is an archipelago located in the south-west Pacific just north of the Tropic of Capricorn $\left(20-23^{\circ} \mathrm{S}\right.$, $164-167^{\circ} \mathrm{E}$ ), about $1500 \mathrm{~km}$ east of Australia and $2000 \mathrm{~km}$ north of New Zealand (Figure 1). It harbours an unique flora that is one of the richest in the world with ca. 3400 native vascular species, of which $75 \%$ are endemic (Morat et al. 2012; Munzinger et al. 2016). The total area of the archipelago is about $18,500 \mathrm{~km}^{2}$, Grande Terre covers about $16,500 \mathrm{~km}^{2}$. Mean annual precipitation ranges from $300 \mathrm{~mm}_{\text {year }}{ }^{-1}$ in the lowlands of the leeward west coast to more than $4000 \mathrm{~mm}$ year $^{-1}$ on some mountain tops and some lowlands of the windward east coast (Météo-France 2007). The subtropical climate is characterised by a long dry season from August to December $\left(<100 \mathrm{~mm} \mathrm{month}^{-1}\right)$. Frost rarely occurs even on the mountain summits (Maitrepierre 2012).

The study sites were located along a line that traverses different precipitation regimes and elevations across Grande Terre from west to east and over Mont Aoupinié $\left(1006 \mathrm{~m}, 21^{\circ} 11^{\prime} \mathrm{S}\right.$ and $\left.165^{\circ} 16^{\prime} \mathrm{E}\right)$. Mont Aoupinié represents one of the largest continuous massifs supporting tropical rainforest in New Caledonia (ca. 68,500 ha,

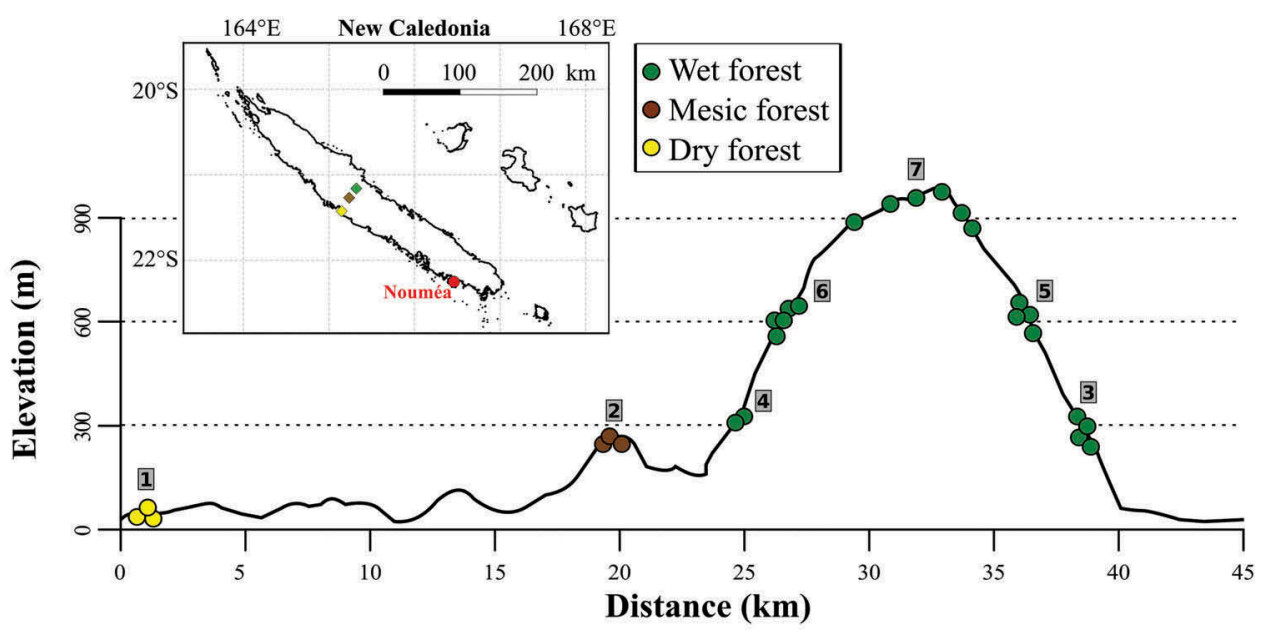

Figure 1. Location of the study sites (grey squares) and plots (circles) across an elevation gradient, New Caledonia. 
Birnbaum et al. 2015). Along this transect, seven sites were located at four elevations, covering both east- and west-exposed mountain sides and the three main forest types present (Figure 1, Table 1). New Caledonian dry forests are located on the leeward, west side below $300 \mathrm{~m}$ elevation and receive less than $1000 \mathrm{~mm} \mathrm{year}^{-1}$ precipitation while rainforest is located above $300 \mathrm{~m}$ elevation and receives between 1300 and $3500 \mathrm{~mm}^{-1}$ precipitation (Jaffré et al. 2012). Mesic forests, located at middle elevations and receiving intermediate precipitation, are still not well characterised in New Caledonia. They show a mixed flora that are intermediate between that of dry forest and rainforest (see Jaffré et al. 2008). Site 1 was represented by the dry forest of Mépouiri (west side, $<50 \mathrm{~m}$ : three plots) which is one of the most preserved dry forests of New Caledonia (Gillespie et al. 2014). Site 2 was located in a mesic forest (west side, 300 m elevation: three plots). Sites 3 and 4 were located in rainforest at about $300 \mathrm{~m}$ elevation on the east (four plots) and west (two plots) sides, respectively. Sites 5 and 6 were in rainforest at $600 \mathrm{~m}$ elevation on east (four plots) and west (five plots) sides, respectively. Site 7 was located at the top of the mountain (rainforest, ca. $900 \mathrm{~m}$ elevation: six plots).

\section{Liana census}

We inventoried lianas in 27 forest plots of 0.04 ha $(20 \mathrm{~m} \times 20 \mathrm{~m})$. One of the sites, site 4 , was represented by only two plots; all other sites were represented by at least three plots (Table 1). In total, 20 of the 27 plots belong to the New Caledonian Plant Inventory and Permanent Plot Network (Ibanez et al. 2014) in which all plants with a diameter at breast height $(\mathrm{DBH}) \geq 5 \mathrm{~cm}$ were inventoried. We increased the existing inventory by seven plots at low elevation for a total of 27 plots. All plots were located on volcano-sedimentary substrate which is the principal substrate type in New Caledonia (about twothirds of the total area). For each plot, we calculated canopy height as the arithmetic mean of the height of three representative trees measured using a TRUPULSE 360R Telemeter.

We inventoried all lianas that were rooted in the plots that had a diameter at point of measurement (i.e. at $1.3 \mathrm{~m}$ from the last substantial rooting point; DPOM) $\geq 1 \mathrm{~cm}$ following the standardised protocol for liana censuses (Gerwing et al. 2006; Schnitzer et al. 2008). We defined lianas as woody plants rooted in the ground throughout life and non-self-supporting when mature (Gerwing et al. 2006). We additionally inventoried all climbing SHE, i.e. Freycinetia (Pandanaceae) and Blechnum (Blechnaceae), as important forest structural components. Indeed, SHE that are not usually included in analyses focused on lianas sensu stricto (Schnitzer et al. 2008) make a significant contribution to the abundance and richness of all climbing plants (broad sense) in montane rainforest in New Caledonian (Jaffré et al. 1994, 2012). It therefore seemed appropriate to include them in our inventories as additional kinds of climbing plants and as forest features that might influence the distribution of lianas sensu stricto. Species of the climbing monocotyledon genus Smilax (Smilacaceae) were also included in the census, despite their non-woody organisation, because of their perennial climbing habit characterised and body size similar to many woody lianas (cf. Schnitzer et al. 2008).

All lianas were tagged with loosely tied stainless steel wire and measured at DPOM. Lianas and SHE were identified in the field or collected for later identifications via local floras and/or by comparison with specimens in the herbarium of New-Caledonia (NOU) at IRD (Nouméa) where vouchers were deposited; $98 \%$ of liana individuals were identified to the species level.

We assigned a climbing mode to each inventoried species in order to analyse the relationships between the functional assemblage of liana communities and forest structure (see Senbeta et al. 2005). Various classifications of liana climbing modes have been proposed in the literature (e.g. see Putz 1984b; Rowe et al. 2006; Isnard and Silk 2009; Gallagher and Leishman 2012). Since climbing mode distribution is known to vary with forest structure and type of support available (Putz 1984b; Nabe-Nielsen 2001), we retained four main climbing modes according to the a priori relation with host tree:

(1) Passive climbers (scramblers; spine/thorn or openhook climbers sensu Darwin 1865): stems that lean and attach insecurely to the support.

(2) Active climbers (hooks sensu Treub 1883, tendrils or sensitive organs): use modified organs (leaves, stipules, leaflets) that are sensitive and coil around the support.

(3) Twiner: the main stem or branches coil around a support.

(4) Root climbers: use adventitious roots to adhere and anchor the climber to supports.

Passive climbing lianas might depend more on the density of supports than on a restricted support diameter (Putz 1984b), while thorn and open-hook climber might preferentially climb on thin supports (Nabe-Nielsen 2001; Koski 2009). Active climbers require supports of small diameter (<7 cm) (Putz 1984b; Senbeta et al. 2005; Parthasarathy et al. 2015) while twining lianas have possibly the widest ranges of diameter for support and can climb larger diameter support than active climbers (Putz 1984b). Root-climbing lianas are able to climb on any tree diameter (Putz 1984b; Putz and Chai 1987).

\section{Data analysis}

We used a species rank-abundance distribution plot to illustrate the sampled liana community and highlight the distribution of different species and climbing modes. We tested whether or not climbing modes affected species abundance distribution using Wilcoxon rank-sum tests.

For each plot, we calculated rarefied richness for a sample of 50 individuals using the $i N E X T$ package for $\mathrm{R}$ 


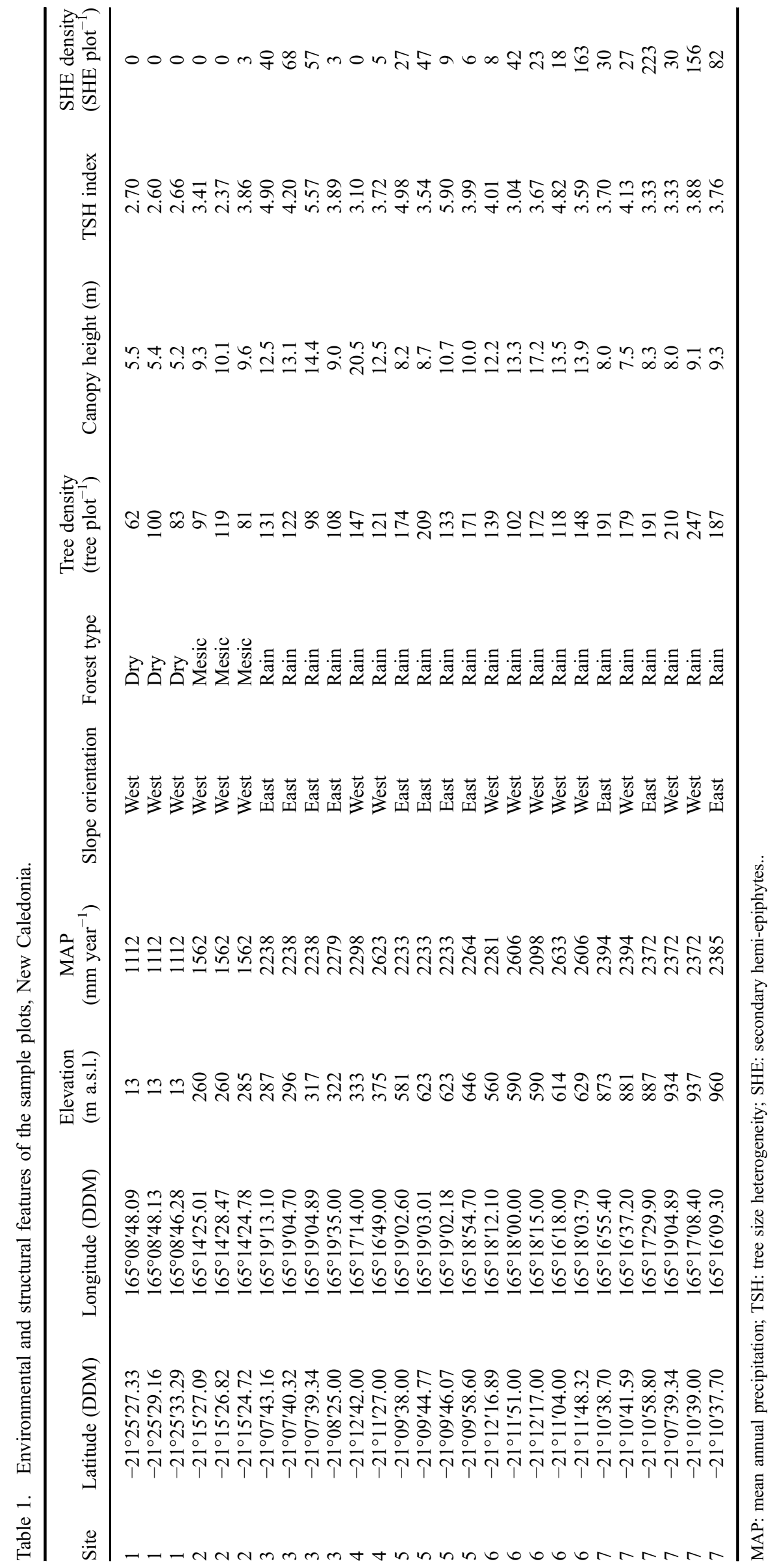


(Chao et al. 2014; Hsieh et al. 2014). For the analyses of richness, we removed plots with less than 10 individuals for which extrapolated rarefied richness was imprecise. This was the case for one plot at site 6 (600 m, west) and two plots at site $7(900 \mathrm{~m})$.

For each plot, we computed a TSH index and tested its effect on liana abundance, richness and climbing modes. The TSH index we chose were the Shannon index equivalent Hill number calculated on the tree DBH distribution (see Buongiorno et al. 1994; McElhinny et al. 2005; Jost 2006). This method has proved to be precise (McElhinny et al. 2005) and insensitive to sample size (Jost 2006). Tree DBH were segregated in 28 classes (in increments of $5 \mathrm{~cm}$ from 5 to $145 \mathrm{~cm} \mathrm{DBH})$ for which we used the Vegetarian package for R (Charney and Record 2012) to calculate the Hill numbers.

We analysed the responses of liana abundance and rarefied richness to plot elevation and plot orientation (east, west) using General Linear Model (GLM) with Poisson and Gaussian distributions. We also investigated patterns of abundance by removing one by one, the five most abundant species to evaluate the importance of dominant species in the liana distribution along the gradient. We then evaluated which factors were responsive for this pattern; we made other GLM analyses with both abiotic (mean annual precipitation) and biotic (canopy height, tree density, TSH index and abundance in SHE) factors as explanatory variables. Abundance data in SHE were log-transformed to fit with validity conditions.

Effects of biotic and abiotic factors on liana floristic dissimilarity were investigated with permutational multivariate analysis of variance (permanova). Using the vegan package for $\mathrm{R}$ (Oksanen et al. 2015), we calculated a dissimilarity matrix between plots with Bray-Curtis index. The analyses were carried out with the dissimilarity matrix as response factor and mean annual precipitation, canopy height, tree density, TSH index and abundance in SHE as explanatory variables (1000 permutations).

We investigated the relationship between climbing modes and forest structural features at two different levels.

(1) At the community level, we used principal component analysis carried out using the package ade 4 for R (Dray and Dufour 2007). We thus investigated correlations between abundance and richness of the four climbing modes and forest structural features.

(2) At the individual level, we investigated the relationship between the DBH of trees (potential support) and the presence of lianas with different climbing modes. To make different potential supports sizes comparable, trees were classified into $5 \mathrm{~cm}$ DBH classes from [5:10] to [140:145]. The DBH distribution of all inventoried trees was used as a null distribution because it represents the expected pattern of liana infestation under the null hypothesis (no preference of lianas for any diameter class). To compare observed and expected patterns of liana infestation, observed distribution of the abundance of lianas as a function of the DBH of the support was plotted against the null distribution.

Permutation tests were carried out to assess the statistical significance of the differences between the observed distribution of the DBH of liana supporting stems and the distribution of the DBH of all trees (H0). To this end, the $\mathrm{DBH}$ of trees was classified into three more inclusive classes (small trees, medium trees and large trees) according to the terciles of the $\mathrm{DBH}$ distribution (first tercile $=7.3 \mathrm{~cm}$ and second tercile $=11.1 \mathrm{~cm}$ ). For each climbing mode, the presence of lianas on trees was permutated, i.e. to each liana we randomly associated a support tree. Permutations were carried out 1000 times and for each permutation the number of lianas on trees of each DBH classes was calculated to produce the H0 distribution. Then, the observed number of lianas on trees of the considered DBH class was compared with the $\mathrm{H} 0$ distribution to test the hypothesis that establishment of lianas is independent of support size.

\section{Results \\ Community structure}

We sampled a total of 992 lianas from 71 species (32 genus, 21 families). Eight individuals (2\%) were identified to genus level, all others were identified to the species level. About $65 \%$ of species were endemics and only two uncommon taxa were considered as non-native (Ipomoea cairica, three individuals, and Lantana camara, two individuals). Moraceae was the most abundant family in terms of number of individuals $(20 \%$ of total individuals, Figure 2a), dominated by Trophis scandens (190 individuals, Figure 3). The second most abundant family was the Apocynaceae (18\% of individuals). This family was more diverse than Moraceae, although also mainly represented by a highly common species Carissa ovata (74 individuals). Neither $C$. ovata nor $T$. scandens are endemic and both formed large multi-stemmed individuals, particularly in the dry forest site.

The most speciose families in our inventory were in decreasing order: Apocynaceae (20 species), Lamiaceae (12 species) and Rubiaceae (10 species). These represented $58 \%$ of all liana species (Figure $2 \mathrm{~b}$ ). These three families were also represented by a large number of individuals (Figure 2a). Twining lianas accounted for almost $75 \%$ of all sampled individuals and species while the three other climbing modes were about equally represented in the remaining $25 \%$ (Figure 3 ). Species abundance was not different following climbing mode classes according to Wilcoxon tests $(P>0.05)$; however, twiners tended to be less abundant than passive climbers $(P=0.034)$.

In our census, the great majority of taxa were rare $(<5$ individuals) or restricted to a narrow elevation gradient. 
(a)

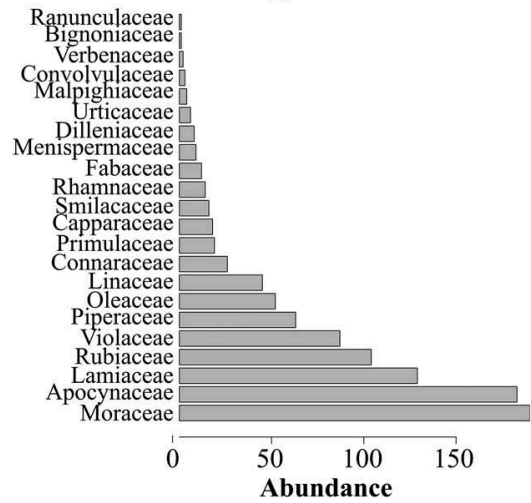

(b)

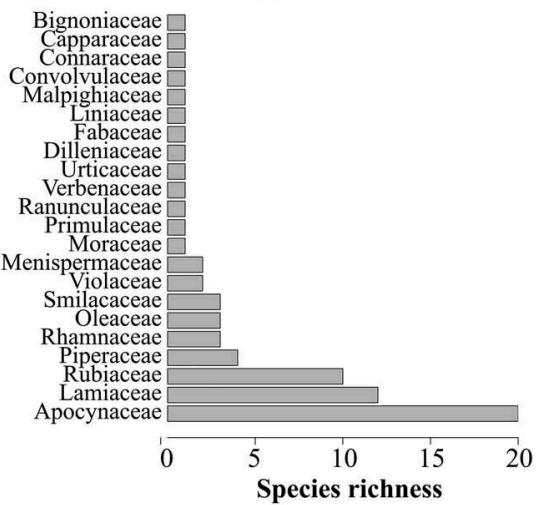

Figure 2. Ranking of families according to their (a) abundance and (b) richness of liana species, New Caledonia.

(a) Ventilago neocaledonica Parsonsia sp. 2
Parsonsia macrophylla
Oxera subverticillata
Oxera baladica
Lantana camara
Hoya limoniaca
Gynochthodes sp. 2
Gouania leratii
Alyxia sp. 1 Tylophora biglandulosa Parsonsia sp. 1

Parsonsia crebriflora

Melodinus balansae Marsdenia tricholepis Jasminum simplicifolium Ipomoea cairica Hypserpa sp. 1

Gynochthodes collina Alyxia leucogyne Stigmaphyllon discolor Melodinus phylliraeoides Smilax orbiculata Piper sp. 2 (DB21) Melodinus aeneus Nothocnide repanda Hypserpa neocaledonica Alyxia tisserantii Oxera robusta

Tetracera billardieri Piper sp. 1 (DB70) Parsonsia affinis Ventilago pseudocalyculata

Smilax purpurata Oxera pulchella Gynochthodes mollis Mezoneuron montrouzieri Jasminum mackeeorum Gynochthodes myrtifolia Agatea pancheri Capparis quiniflora Maesa novocaledonica Gynochthodes billardierei Piper insectifugum Piper comptonii

Rourea balansaeana Jasminum didymum Hugonia jenkinsii Oxera coronata Coelospermum balansanum Oxera morierei Secamone elliptica Agatea rufotomentosa Carissa ovata Trophis scandens (c) Species richness

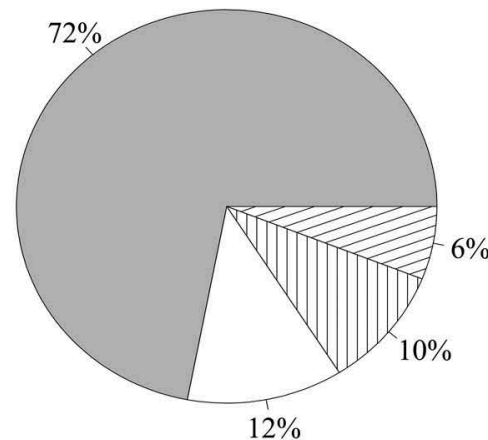

(b) Abundance

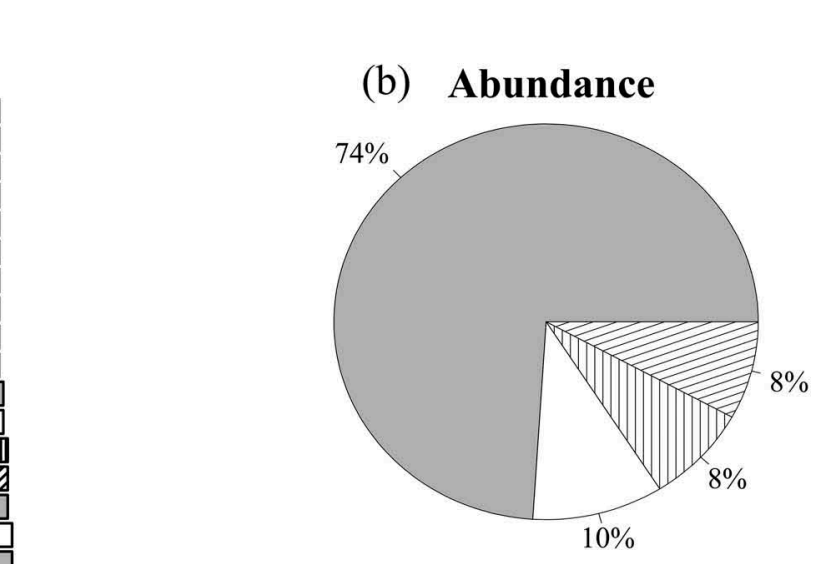

Root climbers

ШD Active climbers Root climbers

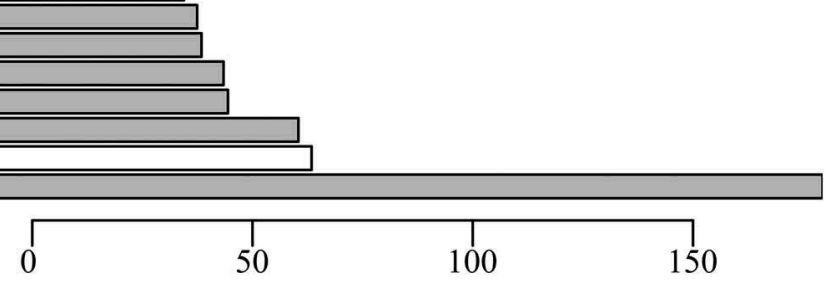

Abundance

Figure 3. (a) Species rank-abundance distribution and climbing modes of lianas ( $n=992$ individuals), New Caledonia. Singletons (16 species) were not included. Relative importance of the different climbing mode groups in (b) abundance and (c) richness of lianas. 
For example, $67 \%$ of the species were in a single elevation belt, $24 \%$ of species are singletons and 14\% are doubletons. Few dominant species such as T. scandens, C. ovata, Agatea rufotomentosa and Hugonia jenkinsii contributed most to the abundance of lianas.

\section{Liana abundance and richness}

Liana abundance varied significantly with elevation, but this was not accompanied by a parallel increase in liana species richness. Controlling for elevation, the abundance and richness of lianas were not significantly different between the west and east sides of the island (ANCOVA: $P=0.126$ and 0.351 , respectively). It must be noted that dry forest at low elevation did not occur at the eastern side.

Liana abundance showed a significant logarithmic decrease with elevation, with a sharp decrease between 0-300 m. This was followed by a more gradual and almost linear decrease up to $900 \mathrm{~m}$ (Figure 4). The decrease in liana abundance with elevation remained significant even after removal, one by one, of the five most abundant species $(P<0.001)$ and the decrease became linear following the removal of the second most abundant species (C. ovata). Liana basal area was strongly correlated with abundance (Spearman correlation test: rho $=0.83$, $P<0.001)$ and thus followed the same logarithmic decrease with elevation (not shown). Rarefied richness tended to peak at mid-elevation; however, this relationship was not significant $(P>0.05$, Figure 5).

The logarithmic decrease in abundance with increasing elevation was significantly related to mean annual precipitation and the abundance of SHE (Table 2). None of the biotic or abiotic variables tested was significantly related to liana richness (Table 2); however, all were significantly positively related to floristic dissimilarity (Permanova, $P<0.013)$.

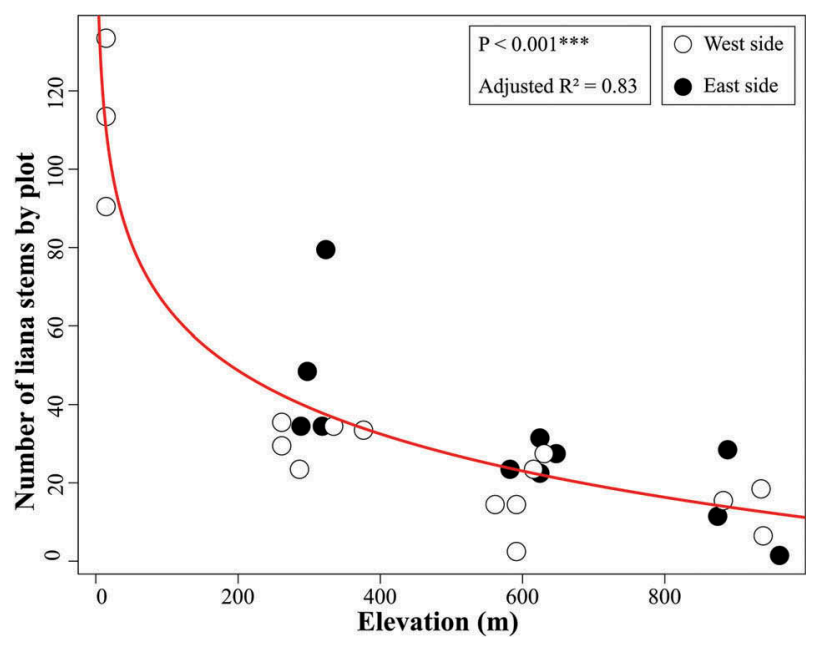

Figure 4. Relationship between liana abundance and elevation on the west and east sides of New Caledonia. (a)

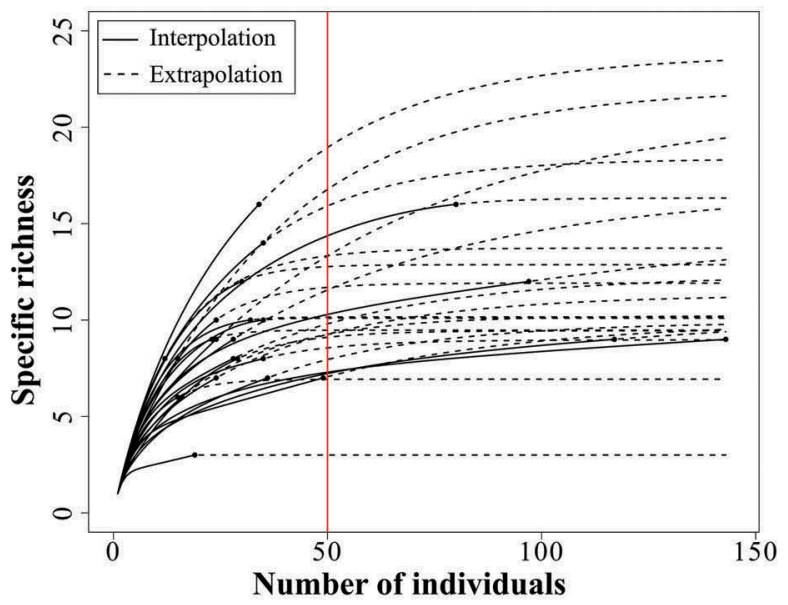

(b)

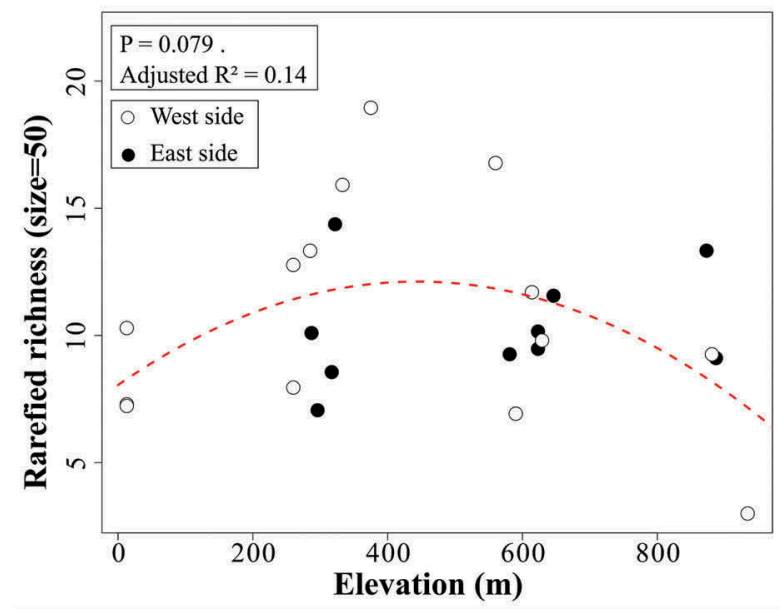

Figure 5. (a) Rarefaction and extrapolation curves for the 27 plots. (b) Relationship between rarefied specific richness for 50 individuals and elevation for west and east sides of New Caledonia.

\section{Climbing modes and forest structure}

Only the passive climbers and twiners appeared to be associated with forest structural variables at the community level (Figure 6). The abundance and richness linked to these climbing modes were positively correlated with the proportion of small trees in the plots (rho >0.55). Others forest structural features were unrelated to climbing mode abundance and richness. At the individual level (all plots combined), lianas were overrepresented on large trees $(>11 \mathrm{~cm} \mathrm{DBH})$ and underrepresented on small trees $(<7.3 \mathrm{~cm} \mathrm{DBH})$, independently of climbing mode (Figure 7).

\section{Discussion}

Our results showed an unequivocal variation in liana abundance with elevation in New Caledonia, with the low elevation dry forest having higher liana abundance, even after removing hyperdominant species from the analysis. Liana abundance was strongly correlated with mean 
Table 2. Generalised linear models with liana abundance and richness as a function of biotic and abiotic conditions, New Caledonia.

\begin{tabular}{lcrrr}
\hline & \multicolumn{2}{c}{ Abundance } & \multicolumn{2}{c}{ Richness } \\
\cline { 2 - 3 } & $P$-value & Estimate & & E-value \\
\hline Canopy height & 0.123 & -0.019 & 0.176 & 0.381 \\
Tree density & 0.342 & 0.001 & 0.139 & -0.059 \\
Tree size heterogeneity & 0.052 & -0.127 & 0.394 & -1.341 \\
SHE abundance & $0.039 *$ & 0.074 & 0.877 & 0.123 \\
MAP & $<2 \mathrm{e}-16^{* * *}$ & -0.003 & 0.249 & 0.007 \\
\hline
\end{tabular}

${ }^{* * *} P<0.001 ; * P<0.05$. MAP: mean annual precipitation; TSH: tree size heterogeneity; SHE: secondary hemi-epiphytes.

annual precipitation but not with the tested forest structural features. Liana richness tended to increase at mid elevation but was not affected by precipitation or local forest

(a) Abundance

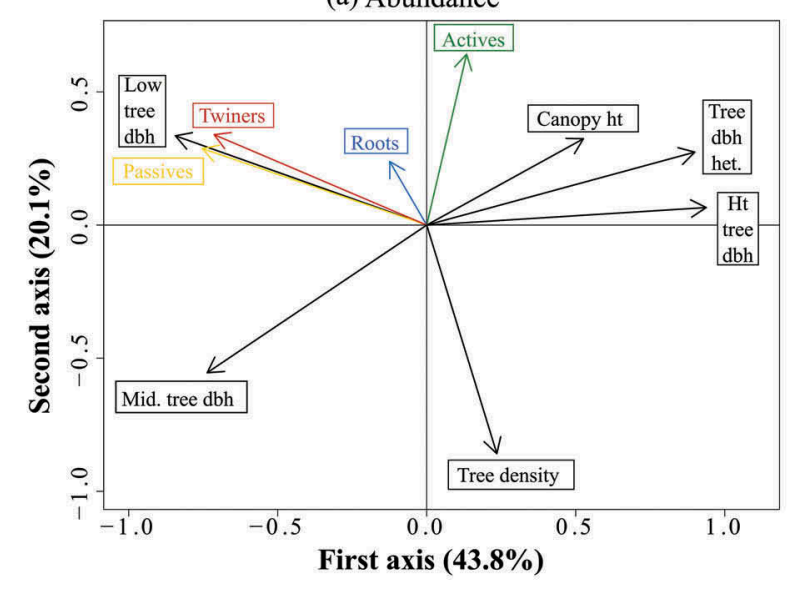

(b) Species richness

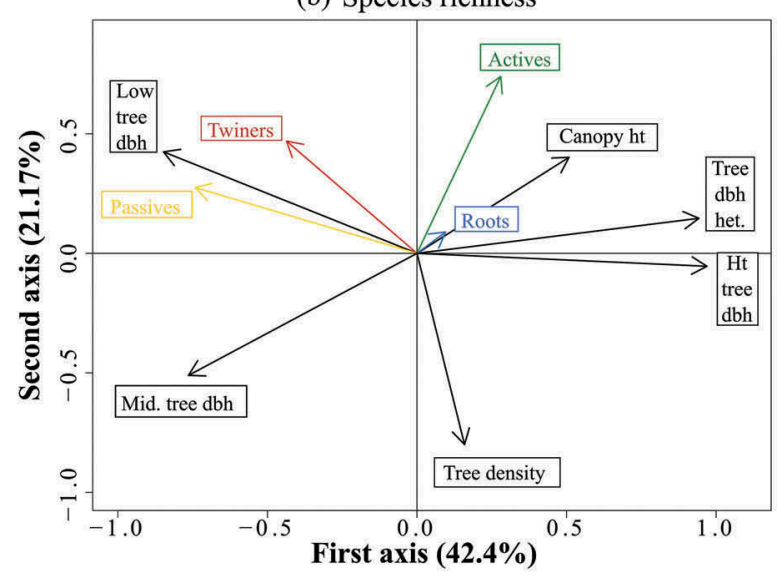

Figure 6. Representation of abundance (a) and richness (b) of climbing modes and of forest structural features on the first two axes of a principal component analysis. Passives, richness or abundance of passive climbers; Twiners, richness or abundance of twiners; Roots, richness or abundance of root climbers; Actives, richness or abundance of active climbers; Canopy ht, canopy height; Tree dbh het., tree size heterogeneity index; Ht tree dbh, proportion of large dbh trees; Mid. Tree dbh, proportion of medium dbh trees; Low tree dbh, proportion of low dbh trees. structural features in contrast to floristic dissimilarity on which all tested explanatory variables had positive effect. Contrary to our former hypothesis, we did not find a clear relationship between climbing mode distribution and local forest structure.

\section{Community structure}

At the community level, few species-rich families (Apocynaceae, Lamiaceae and Rubiaceae) dominated the community both in terms of abundance and richness. These families are mainly twining which result in a dominance of twining climbers in the census (richness and abundance). This result is in accordance with several studies worldwide reporting that twining is the predominant climbing mode (Putz 1984b; Putz and Chai 1987; Parthasarathy et al. 2004; Burnham and Revilla-Minaya 2011). In our census, the abundance of twiners was not explained by their climbing modes per se, many twining species being often found in low abundance but rather by the greater overall richness of twining species.

As commonly reported for liana communities (Dewalt et al. 2000; Mascaro et al. 2004; Parthasarathy et al. 2004), a limited subset of species dominates the community, the top three species representing $35 \%$ of all individuals. No species showed a wide ecological range, and many species were found as singletons (24\%) or doubletons (14\%). Species rarity and habitat heterogeneity seem to contribute strongly to beta diversity along the gradient as illustrated by the strong effect of all environmental variables on liana floristic dissimilarity. This marked floristic dissimilarity could however result from small plot size and an important contribution of rare species. A similar pattern has been found for tree species in the New Caledonian permanent plots network (Ibanez et al. 2014). However, a greater number of plots along the elevation gradient in New Caledonia would be necessary to confirm the pattern of floristic dissimilarity.

\section{Liana abundance}

As hypothesised, liana abundance was related positively to decreasing precipitation. Minimum temperature is an 


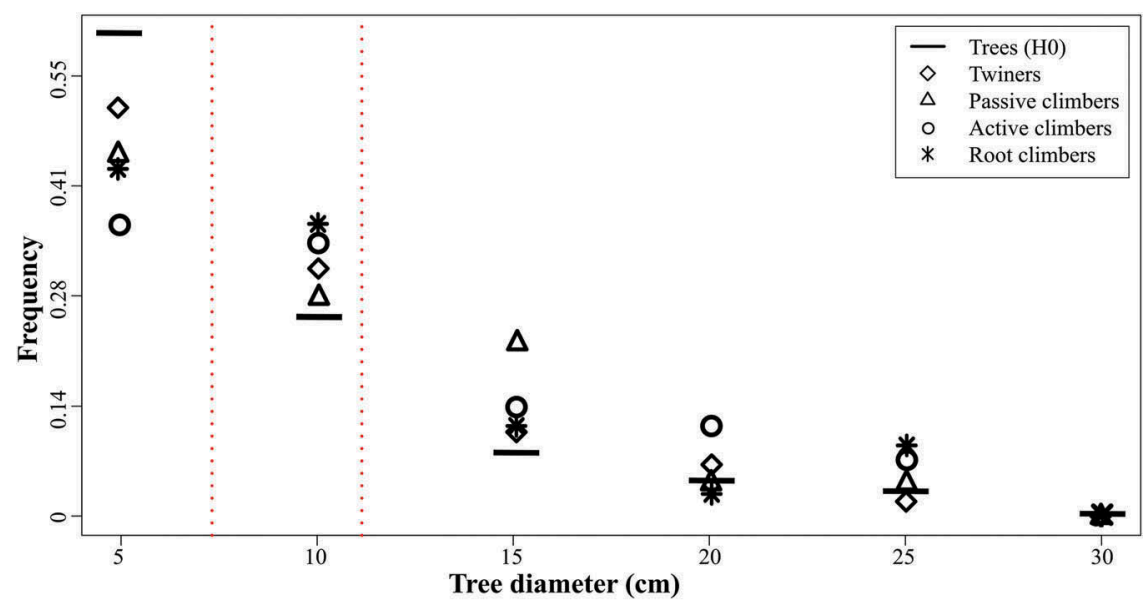

Figure 7. Distribution patterns of the abundance of lianas as a function of the size (DBH) of the supports and for different climbing modes. Horizontal traits represent the distribution pattern of tree diameter and thus corresponds to the null hypothesis (H0). Climbing modes below H0 were underrepresented on the tree diameter class considered while climbing mode above H0 were overrepresented. Vertical dashed lines represent the terciles of the tree diameter distribution $(Q 0.33=7.32 \mathrm{~cm} ; Q 0.66=11.14 \mathrm{~cm})$ and define the class used for permutation tests whose results are in the Table 3. For more visibility, only the left part of the total distribution has been presented ( $90 \%$ of all lianas and trees).

Table 3. The results of permutation tests for tree size preference of lianas with different climbing modes.

\begin{tabular}{lccc}
\hline & \multicolumn{1}{c}{ Small trees } & Medium trees & Big trees \\
\cline { 2 - 4 } & $(\mathrm{DBH}<7.32 \mathrm{~cm})$ & $(7.32 \mathrm{~cm} \leq \mathrm{DBH}<11.14 \mathrm{~cm})$ & $(\mathrm{DBH} \geq 11.14 \mathrm{~cm})$ \\
\hline Twiners & $<0.001^{* * *}$ & 0.103 & $0.027^{*}$ \\
Passive climbers & $0.016^{*}$ & 0.227 & 0.099 \\
Active climbers & $0.01^{*}$ & 0.459 & $0.003^{* *}$ \\
Root climbers & 0.098 & 0.326 & $0.008^{* *}$ \\
\hline
\end{tabular}

***P $<0.001 ; * * P<0.01 ; * P<0.05$.

important environmental factor that co-varies with elevation and which could influence liana distribution along short elevation gradients (Jiménez-Castillo et al. 2007; Alves et al. 2011; Orihuela et al. 2014; Fadrique and Homeier 2016). In New Caledonia, however temperature is probably not a main factor since frost rarely occurs, even at $1000 \mathrm{~m}$ elevation (Maitrepierre 2012). At low elevations on the west coast, the vegetation consists of dry semi-deciduous forests with a long dry season (Jaffré et al. 1993; Maitrepierre 2012). Dry forest in New Caledonia often shows signs of anthropogenic disturbance (Bouchet et al. 1995). These conditions are known to positively affect liana abundance and basal area (Gentry 1991; Schnitzer 2005; DeWalt et al. 2010, 2015; Parthasarathy et al. 2015; Schnitzer et al. 2015a). Thus, the decrease of liana abundance with elevation is probably due to a combination of mean annual rainfall, seasonality and decreasing disturbance.

The increase in SHE density and decrease in liana abundance with increasing elevation could reflect climatic niche differentiation rather than host competition. Contrary to many lianas, climbing hemi-epiphytes are likely to be favoured in moist conditions (Putz and Holbrook 1986; Gentry and Dodson 1987; Benzing
1990). Gentry and Dodson (1987) have further suggested that lianas are replaced by hemi-epiphytes in moist environments because they trap humidity better. In our study, abundance in SHE was positively correlated with precipitation (rho $=0.55$ ) and SHE were absent from dry forest plots. This niche differentiation between lianas and climbing hemi-epiphytes might be a particularly important factor on some tropical and subtropical islands where there is a steep moisture gradient with elevation, and the occurrence of cloud forest (Carlquist 1974). The few studies carried out on such islands indeed have suggested that climbing hemi-epiphytes are abundant whereas lianas are less represented (Kelly 1985; DeWalt et al. 2015). Thus, climbing hemiepiphytes appear to be a climbing life form that contribute more to forest structure and functional diversity in such islands in montane forests. Islands with a large enough elevation gradient offer an unparalleled opportunity to analyse climbing plant s.l. distributions and to test how distributions of lianas might be related to moisture availability. A further hypothesis to test would be to analyse whether lianas are sensitive to relatively low vapour pressure deficit and become less competitive when evapotranspiration becomes lower. 


\section{Liana richness and climbing modes}

While we predicted that local forest structural features affect liana species richness, we did not find any relationship between the tested factors and liana richness in New Caledonian forest plots. This highlights the fact that the real structural relation between liana diversity and local factors is probably highly complex. This is amply illustrated by the disagreement between different studies and the relatively weak correlations of liana richness with biotic or abiotic variables compared with correlations of liana abundance or basal area (e.g. Balfour and Bond 1993; Ibarra-Manríquez and Martínez-Ramos 2002; Parthasarathy et al. 2004; DeWalt et al. 2015).

The hypothesis that TSH should promote liana richness through the diversity of climbing niches for different climbing modes was not confirmed. At the community level, we found only a weak relationship between climbing mode and forest features (tree density, canopy height, tree size). Instead, the structural relationship between liana and host seems to be opportunistic rather than deterministic. At the individual level we found more lianas than expected occupying large trees $(>10 \mathrm{~cm} \mathrm{DBH})$ and fewer climbers on small diameter trees $(<7.3 \mathrm{~cm} \mathrm{DBH})$, independently of climbing mode. As such, although some lianas are favoured by small diameter supports (passive climbers and twiners in our study), the presence of large trees $(>10 \mathrm{~cm} \mathrm{DBH})$ increases the probability of liana establishment. This process probably blurs any deterministic relationship between liana and host. Large trees are usually older and thus had a longer exposure to lianas (Nabe-Nielsen 2001; Pérez-Salicrup and Sork 2001; Fadrique and Homeier 2016) or simply can provide more space for establishment. Moreover, the presence of one liana can facilitate the establishment of other lianas by providing more structural opportunities (Putz and Chai 1987; Pérez-Salicrup and Sork 2001; Ibarra-Manríquez and Martínez-Ramos 2002). Our results illustrate the difficulty of understanding relationships between climbing modes, diversity and forest structural features; all of which may vary depending on spatial scale, biogeography and forest dynamics.

In our study, species richness was more variable at mid elevation, and we suspect that other local factors also act on liana local richness. Notably, small-scale perturbations such as canopy gaps are key to promoting local liana richness (Schnitzer and Carson 2001; Schnitzer et al. 2015a). Although perturbation rates are expected to be linked with forest structural characteristics, the small size of the plots in our design was probably a limiting factor in capturing such information.

\section{Conclusion}

In New Caledonia, as in many other tropical and subtropical sites, lianas are particularly abundant in drier areas.
This supports the hypothesis that liana abundance should increase locally with increasing seasonal drought. Our results also suggest that climbing hemi-epiphytes, which are generally not considered in studies on liana ecology, could be important to understand the assemblage of climbing plants communities, especially in high-elevation tropical islands and perhaps in tropical continental mountains. Most species had a restricted ecological range in our survey. Beyond our small plot sampling, this supports the existence of a high beta diversity and highlights the importance of integrating full elevation gradients in biodiversity conservation strategies. This is particularly important for such isolated islands where micro-endemism is high and available habitats are restricted.

\section{Acknowledgements}

We are very grateful to the Province Sud of New Caledonia (Vivaldi program) and the Grand Observatoire du Pacifique Sud (GOPS) for funding. We are grateful to W. Nigote, J. Girardi and M. Magat for help on the field and to J. Fambart for help at the NOU herbarium. Thank you to Nick Rowe for revise the wording of the manuscript. We also thank to all the staff of UMR AMAP of Nouméa for help and support.

\section{Disclosure statement}

No potential conflict of interest was reported by the authors.

\section{Funding}

This work was supported by the Grand Observatoire du Pacifique Sud (Clivenc Project); Province Sud of New Caledonia (Vivaldi program); UMR AMAP.

\section{ORCID}

David Bruy (D) http://orcid.org/0000-0002-7339-0375

Thomas Ibanez (D) http://orcid.org/0000-0002-3192-1721

Jérôme Munzinger (D) http://orcid.org/0000-0001-5300-2702

Sandrine Isnard (D) http://orcid.org/0000-0003-3142-2671

\section{Notes on contributors}

David Bruy is a Ph.D. student in plant systematic and evolution. $\mathrm{He}$ is interested in processes responsive for plant diversity patternsand use the New Caledonian flora as a model system.

Thomas Ibanez is a postdoctoral researcher. He is interested in the assembly and dynamics of forest communities as well as their distribution and diversity in tropical rainforests.

Jérôme Munzinger is a researcher. His research is focused on the systematics, origin and conservation of the New Caledonian flora.

Sandrine Isnard is a functional biologist whose research focuses on tropical ecosystem diversity and plant structure and function. 


\section{References}

Alves LF, Assis MA, Melis J, Barros ALS, Vieira SA, Martins FR, Martinelli LA, Joly CA. 2011. Variation in liana abundance and biomass along an elevational gradient in the tropical Atlantic Forest (Brazil). Ecological Research. 27:323-332.

Baars R, Kelly D, Sparrow AD. 1998. Liane distribution within native forest remnants in two regions of the south island, New Zealand. New Zealand Journal of Ecology. 22:71-85.

Balfour DA, Bond WJ. 1993. Factors limiting climber distribution and abundance in a southern African forest. Journal of Ecology. 81:93-99.

Benzing DH. 1990. Vascular epiphytes. Cambridge (United Kingdom): Cambridge University Press.

Birnbaum P, Ibanez T, Vandrot H, Blanchard E, Hequet V, Chambrey C, Pouteau R. 2015. Les forêts humides de la province Nord, Nouvelle-Calédonie. Synthèse des travaux de recherche 2012-2015. Nouméa (New Caledonia): Edition IAC.

Bouchet P, Jaffré T, Veillon J-M. 1995. Plant extinction in New Caledonia: protection of sclerophyll forests urgently needed. Biodiversity and Conservation. 4:415-428.

Buongiorno J, Dahir S, Lu H-C, Lin C-R. 1994. Tree size diversity and economic returns in uneven-aged forest stands. Forest Science. 40:83-103.

Burnham RJ, Revilla-Minaya C. 2011. Phylogenetic influence on twining chirality in lianas from Amazonian Peru. Annals of the Missouri Botanical Garden. 98:196-205.

Campbell M, Laurance WF, Magrach A. 2015. Ecological effects of lianas in fragmented forests. In: Schnitzer SA, Bongers F, Burnham RJ, Putz FE, editors. Ecology of lianas. Chichester (UK): John Wiley \& Sons, Ltd. p. 443-450.

Carlquist S. 1974. Island biology. New York (USA): Columbia University Press.

Chao A, Gotelli NJ, Hsieh TC, Sander EL, Ma KH, Colwell RK, Ellison AM. 2014. Rarefaction and extrapolation with Hill numbers: a framework for sampling and estimation in species diversity studies. Ecological Monographs. 84:45-67.

Charney N, Record S 2012. Vegetarian: jost diversity measures for community data. $\mathrm{R}$ package version 1.2. [cited 2016 May 23]. http://CRAN.R-project.org/package=vegetarian.

Darwin C. 1865 . On the movements and habits of climbing plants. Botanical Journal of the Linnean Society (Botany). 9:1-118.

DeWalt SJ, Schnitzer SA, Alves LF, Bongers F, Burnham RJ, Cai Z, Carson WP, Chave J, Chuyong GB, Costa FRC, et al. 2015. Biogeographical patterns of liana abundance and diversity. In: Schnitzer SA, Bongers F, Burnham RJ, Putz FE, editors. Ecology of lianas. Chichester (UK): John Wiley \& Sons, Ltd. p. 131-146.

DeWalt SJ, Schnitzer SA, Chave J, Bongers F, Burnham RJ, Cai Z, Chuyong G, Clark DB, Ewango CEN, Gerwing JJ, et al. 2010. Annual rainfall and seasonality predict pan-tropical patterns of liana density and basal area. Biotropica. 42:309-317.

Dewalt SJ, Schnitzer SA, Denslow JS. 2000. Density and diversity of lianas along a chronosequence in a central Panamanian lowland forest. Journal of Tropical Ecology. 16:1-19.

Dray S, Dufour A-B. 2007. The ade4 package: implementing the duality diagram for ecologists. Journal of Statistical Software. 22:1-20.

Fadrique B, Homeier J. 2016. Elevation and topography influence community structure, biomass and host tree interactions of lianas in tropical montane forests of southern Ecuador. Journal of Vegetation Science. 27:958968.
Gallagher RV, Leishman MR. 2012. A global analysis of trait variation and evolution in climbing plants. Journal of Biogeography. 39:1757-1771.

Gentry AG, Dodson CH. 1987. Diversity and biogeography of neotropical vascular epiphytes. Annals of Missouri Botanical Garden. 74:205-233.

Gentry AG. 1991. The distribution and evolution of climbing plants. In: Putz FE, Mooney HA, editors. The biology of vines. Cambridge (UK): Cambridge University Press. p. 73-97.

Gerwing JJ, Farias DL. 2000. Integrating liana abundance and forest stature into an estimate of total aboveground biomass for an eastern Amazonian forest. Journal of Tropical Ecology. 16:327-335

Gerwing JJ, Schnitzer SA, Burnham RJ, Bongers F, Chave J, DeWalt SJ, Ewango CEN, Foster R, Kenfack D, MartínezRamos M, et al. 2006. A standard protocol for liana censuses. Biotropica. 38:256-261.

Gillespie TW, ONeill K, Keppel G, Pau S, Meyer JY, Price JP, Jaffré T. 2014. Prioritizing conservation of tropical dry forests in the Pacific. Oryx. 48:337-344.

Granados J, Korner C. 2002. In deep shade, elevated $\mathrm{CO}_{2}$ increases the vigor of tropical climbing plants. Global Change Biology. 8:1109-1117.

Hegarty EE, Caballé G. 1991. Distribution and abundance of vines in forest communities. In: Putz FE, Mooney HA, editors. The biology of vines. Cambridge (UK): Cambridge University Press. p. 313-335.

Hegarty EE. 1991. Vine-host interactions. In: Putz FE, Mooney HA, editors. The biology of vines. Cambridge (UK): Cambridge University Press. p. 357-375.

Homeier J, Englert F, Leuschner C, Weigelt P, Unger M. 2010. Factors controlling the abundance of lianas along an altitudinal transect of tropical forests in Ecuador. Forest Ecology and Management. 259:1399-1405.

Hsieh TC, Ma KH, Chao A 2014. iNEXT: iNterpolation and EXTrapolation for species diversity. $\mathrm{R}$ package version 2.0. [cited 2015 May 5]. http://chao.stat.nthu.edu.tw/blog/ software-download.

Ibanez T, Munzinger J, Dagostini G, Hequet V, Rigault F, Jaffré T, Birnbaum P. 2014. Structural and floristic diversity of mixed tropical rain forest in New Caledonia: newdata from the New-Caledonian Plant Inventory and Permanent PlotNetwork (NC-PIPPN). Applied Vegetation Science. 17:386-397.

Ibarra-Manríquez G, Martínez-Ramos M. 2002. Landscape variation of liana communities in a neotropical rain forest. Plant Ecology. 160:91-112.

Ingwell LL, Wright SJ, Becklund KK, Hubbell SP, Schnitzer SA. 2010. The impact of lianas on 10 years of tree growth and mortality on Barro Colorado Island, Panama. Journal of Ecology. 98:879-887.

Isnard S, Silk WK. 2009. Moving with climbing plants from Charles Darwin's time into the 21st century. American Journal of Botany. 96:1205-1221.

Jaffré T, Morat P, Veillon J-M. 1993. Etude floristique et phytogéographique de la forêt sclérophylle de NouvelleCalédonie. Paris: Bulletin du Museum National d'Histoire Naturelle 4e Serie. p. 107-146.

Jaffré T, Morat P, Veillon J-M. 1994. La Flore: caractéristiques et composition floristique des principales formations végétales. Bois Et Forêts Des Tropiques. 242:7-30.

Jaffré T, Rigault F, Munzinger J. 2008. Identification and characterization of floristic groups in dry forests relicts of a West Coast region of New Caledonia. Pacific Conservation Biology. 14:128-145.

Jaffré T, Rigault F, Munzinger J. 2012. La végétation. In: Bonvallot J, Gay J-C, Habert É, editors. Atlas de la Nouvelle-Calédonie Marseille (France)-Nouméa (New Caledonia): IRD-Congrès de la Nouvelle-Calédonie. Marseille (France): Institut de 
Recherchepour le Développement (IRD); Nouméa (New Caledonia): Congrès de la Nouvelle-Calédonie; p. 77-80.

Jiménez-Castillo M, Lusk CH. 2013. Vascular performance of woody plants in a temperate rain forest: lianas suffer higher levels of freeze-thaw embolism than associated trees. Functional Ecology. 27:403-412.

Jiménez-Castillo M, Wiser SK, Lusk CH. 2007. Elevational parallels of latitudinal variation in the proportion of lianas in woody floras. Journal of Biogeography. 34:163-168.

Jost L. 2006. Entropy and diversity. Oikos. 113:363-375.

Kelly DL. 1985. Epiphytes and climbers of a Jamaican rain forest: vertical distribution, life forms and life histories. Journal of Biogeography. 12:223-241.

Kier G, Kreft H, Lee TM, Jetz W, Ibisch PL, Nowicki C, Mutke J, Barthlott W. 2009. A global assessment of endemism and species richness across island and mainland regions. Proceedings of the National Academy of Sciences. 106:9322-9327.

Korner C. 2007. The use of 'altitude' in ecological research. Trends in Ecology and Evolution. 22:569-574.

Koski MH. 2009. Climbing through changing forests: is liana diversity or morphology affected by forest age or precipitation?Ann Arbor (MI): University of Michigan.

Maitrepierre L. 2012. Les types de temps et les cyclones, les éléments du climat. In: Bonvallot J, Gay J-C, Habert E, editors. Atlas de la Nouvelle-Calédonie Marseille (France)Nouméa (New Caledonia): IRD-Le congrès de la NouvelleCalédonie. Marseille (France): Institut de Recherchepour le Développement (IRD); Nouméa (New Caledonia): Congrès de la Nouvelle-Calédonie; p. 15-22.

Mascaro J, Schnitzer SA, Carson WP. 2004. Liana diversity, abundance, and mortality in a tropical wet forest in Costa Rica. Forest Ecology and Management. 190:3-14.

McElhinny C, Gibbons P, Brack C, Bauhus J. 2005. Forest and woodland stand structural complexity: its definition and measurement. Forest Ecology and Management. 218:1-24.

Météo-France. 2007. Atlas climatique de la Nouvelle Calédonie METEO-France en Nouvelle Calédonie. Noumea (New Caledonia): METEO-France.

Morat P, Jaffré T, Tronchet F, Munzinger J, Pillon Y, Veillon J-M, Chalopin M. 2012. The taxonomic database « FLORICAL " and characteristics of the indigenous flora of New Caledonia. Adansonia Ser. 3:177-219.

Munzinger J, Morat P, Jaffré T, Gâteblé G, Pillon Y, Tronchet F, Veillon J-M,Chalopin M. 2016. FLORICAL: checklist of the vascular indigenous flora of New Caledonia. vers. 22. IV.2016. [cited 2017 Jun 17]. http://www.botanique.nc/herb ier/florical.

Myers N, Mittermeier RA, Mittermeier CG, Gab DF, Kent J. 2000. Biodiversity hotspots for conservation priorities Nature. 403:853-858.

Nabe-Nielsen J. 2001. Diversity and distribution of lianas in a Neotropical rain forest, Yasuní National Park, Ecuador. Journal of Tropical Ecology. 17:1-19.

Oksanen J, Blanchet FG, Kindt R, Legendre P, Minchin PR, O'Hara RB, Simpson GL, Solymos P, Stevens MHH, Wagner H 2015. Vegan: community ecology package. R package version 2.3-2. [cited 2016 Feb 10]. http://CRAN. R-project.org/package=vegan. R package version 2.3-2 ed. Ordination methods, diversity analysis and other functions for community and vegetation ecologists.

Orihuela RLL, Molz M, Waechter JL. 2014. Links between environmental factors and hemiepiphytes along a slope of subtropical Atlantic forest. Nordic Journal of Botany. 32:358-368.

Parthasarathy N, Muthuramkumar S, Muthumperumal C, Vivek P, Ayyappan N, Sridhar Reddy M. 2015. Liana composition and diversity among tropical forest types of peninsular India. In: Schnitzer SA, Bongers F, Burnham RJ, Putz FE, editors. Ecology of lianas. Chichester (UK): John Wiley \& Sons, Ltd. p. 36-49.

Parthasarathy N, Muthuramkumar S, Sridhar Reddy M. 2004. Patterns of liana diversity in tropical evergreen forests of peninsular India. Forest Ecology and Management. 190:15-31.

Pérez-Salicrup DR, Schnitzer S, Putz FE. 2004. Community ecology and management of lianas. Forest Ecology and Management. 190:1-2.

Pérez-Salicrup DR, Sork VL. 2001. Lianas and trees in a liana forest of Amazonian Bolivia. Biotropica. 33:34-47.

Phillips OL, Martinez RV, Arroyo L, Baker TR, Killeen T, Lewis SL, Malhi Y, Mendoza AM, Neil D, Vargas PN, et al. 2002. Increasing dominance of large lianas in Amazonian forests. Nature. 418:770-774.

Phillips OL, Vásquez Martínez R, Monteagudo Mendoza A, Baker TR, Núñez Vargas P. 2005. Large lianas as hyperdynamic elements of the tropical forest canopy. Ecology. $86: 1250-1258$.

Putz FE. 1984a. How trees avoid and shed lianas. Biotropica. 16:19-23.

Putz FE. 1984b. The natural history of lianas on Barro Colorado Island, Panama. Ecology. 65:1713-1724.

Putz FE, Chai P. 1987. Ecological studies of lianas in Lambir National Park, Sarawak, Malaysia. Journal of Ecology. 75:523-531.

Putz FE, Holbrook NM. 1986. Notes on the natural history of hemiepiphytes. Selbyana. 9:61-69.

Putz FE, Holbrook NM. 1991. Biomechanical studies of vines. In: Putz FE, Mooney HA, editors. The biology of vines. Cambridge (UK): Cambridge University Press. p. 73-97.

Rice K, Brokaw N, Thompson J. 2004. Liana abundance in a Puerto Rican forest. Forest Ecology and Management. 190:33-41.

Rowe NP, Isnard S, Gallenmüller F, Speck T. 2006. Diversity of mechanical architectures in climbing plants: an ecological perspective. In: Herrel A, Speck T, Rowe NP, editors. Ecology and biomechanics: a mechanical approach to the ecology of animals and plants. Boca Raton (FL): CRC Press LLC. p. 35-59.

Schnitzer SA. 2005. A mechanistic explanation for global patterns of liana abundance and distribution. The American Naturalist. 166:262-276.

Schnitzer SA, Bongers F. 2002. The ecology of lianas and their role in forests. Trends in Ecology \& Evolution. 17:223-230.

Schnitzer SA, Bongers F. 2011. Increasing liana abundance and biomass in tropical forests: emerging patterns and putative mechanisms. Ecology Letters. 14:397-406.

Schnitzer SA, Carson WP. 2001. Treefall gaps and the maintenance of species diversity in a tropical forest. Ecology. 82:913-919.

Schnitzer SA, Mangan SA, Hubbell SP. 2015a. The lianas of Barro Colorado Island, Panama. In: Schnitzer SA, Bongers F, Burnham RJ, Putz FE, editors. Ecology of lianas. Chichester (UK): John Wiley \& Sons, Ltd. p. 76-90.

Schnitzer SA, Putz FE, Bongers F, Kroening K. 2015b. The past, present, and potential future of liana ecology. In: Schnitzer SA, Bongers F, Burnham RJ, Putz FE, editors. Ecology of lianas. Chichester (UK): John Wiley \& Sons, Ltd. p. $1-10$.

Schnitzer SA, Rutishauser S, Aguilar S. 2008. Supplemental protocol for liana censuses. Forest Ecology and Management. 255:1044-1049.

Schnitzer SA. 2015. Increasing liana abundance in neotropical forests: causes and consequences. In: Schnitzer SA, Bongers F, Burnham RJ, Putz FE, editors. Ecology of lianas. Chichester (UK): John Wiley \& sons, Ltd. p. 451-464. 
Senbeta F, Schmitt C, Denich M, Demissew S, Vlek PLG, Preisinger H, Woldemariam T, Teketay D. 2005. The diversity and distribution of lianas in the Afromontane rain forests of Ethiopia. Diversity and Distributions. 11:443452.

Sfair JD, Martins FR. 2011. The role of heterogeneity on climber diversity: is liana diversity related to tree diversity? Global Journal of Biodiversity Science and Management. 1:1-10.

Talley SM, Setzer WN, Jackes BR. 1996. Host association of two adventitious-root-climbing vines in a North Queensland tropical rain forest. Biotropica. 28:356-366.

Taylor S, Kumar L. 2016. Global climate change impacts on Pacific islands terrestrial biodiversity: a review. Tropical Conservation Science. 9:203-223.
Toledo-Aceves T. 2015. Above- and belowground competition between lianas and trees. In: Schnitzer SA, Bongers F, Burnham RJ, Putz FE, editors. Ecology of lianas. Chichester (UK): John Wiley \& Sons, Ltd. p. 147-163.

Treub M. 1883. Sur une nouvelle catégorie de plantes grimpantes. Annales Du Jardin Botanique De Buitenzorg. 3:44-75.

van der Heijden GMF, Phillips OL. 2008. What controls liana success in Neotropical forests? Global Ecology and Biogeography. 17:372-383.

Wright SJ, Calderon O, Hernandez A, Paton S. 2004. Are lianas increasing in importance in tropical forests? A 17-year record from Panama. Ecology. 85:484489.

Zotz G. 2013. 'Hemiepiphyte': a confusing term and its history. Annals of Botany. 111:1015-1020. 